\title{
Influence of Intrauterine Growth Restriction on Airway Development in Fetal and Postnatal Sheep
}

\author{
DHARSHINI WIGNARAJAH, MEGAN L. COCK, KENT E. PINKERTON, AND \\ RICHARD HARDING \\ Fetal and Neonatal Research Group, Department of Physiology, Monash University, Victoria 3800, \\ Australia [D.W., M.L.C., R.H.]; Institute of Toxicology and Environmental Health, University of \\ California-Davis, Davis, California 95616, U.S.A. [K.E.P.]
}

\begin{abstract}
Epidemiologic studies suggest that intrauterine growth restriction (IUGR) can lead to impaired lung function, yet little information exists on the effects of IUGR on airway development. Our objectives were to characterize morphometrically effects of IUGR on airway structure in the fetus and to determine whether alterations persist into postnatal life. We used two groups of sheep, each with appropriate controls; a fetal group was subjected to IUGR by restriction of placental function from 120 to $140 \mathrm{~d}$ (term $\sim 147 \mathrm{~d}$ ), and a postnatal group, killed $8 \mathrm{wk}$ after birth, was subjected to IUGR from $120 \mathrm{~d}$ to birth at term. In both fetuses and postnatal lambs, IUGR did not alter lung weight relative to body weight. In IUGR fetuses, the luminal areas and basement membrane perimeters of the trachea and larger bronchi (generations $0-8$, trachea $=0$ ) were smaller than in controls. Airway wall areas, relative to basement membrane perimeters, were reduced in IUGR fetuses compared with controls, largely due to reduced areas of cartilage and epithelium. At 8 wk after birth, there were no significant differences in airway dimensions between IUGR and control lambs. However, the number of profiles of bronchial submucosal glands, relative to basement membrane perimeters, was lower in IUGR lambs than in controls and the area of epithelial mucin was increased. We conclude that restriction of fetal growth during late gestation impairs the growth of bronchial walls that could affect airway compliance in
\end{abstract}

\section{ABSTRACT}

the immediate postnatal period. Although airway growth deficits are reversed by $8 \mathrm{wk}$, alterations in mucus elements persist. (Pediatr Res 51: 681-688, 2002)

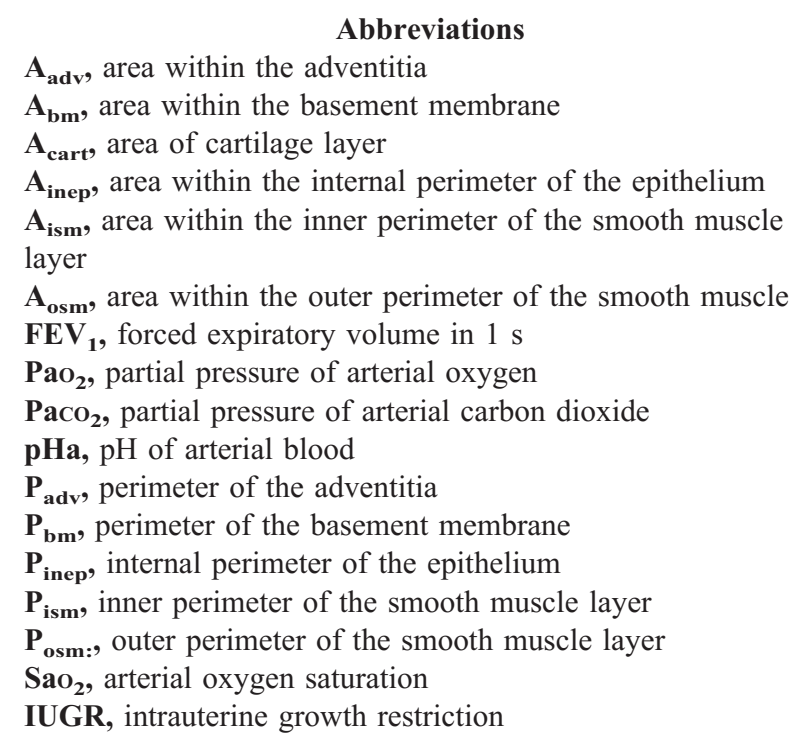

Low birth weight is now recognized to be a risk factor for impaired lung function during postnatal life. A growing body of epidemiologic evidence suggests that intrauterine factors that retard fetal growth and lead to low birth weight can adversely affect lung function during infancy (1-3), childhood $(4-6)$, and adulthood $(7,8)$. It has been suggested that factors that restrict fetal growth, such as reduced placental delivery of nutrients and oxygen to the fetus, may alter the development of

Received August 1, 2001; accepted March 6, 2002.

Correspondence: Richard Harding, Ph.D., D.Sc., Department of Physiology, Monash University, Victoria 3800, Australia; e-mail: richard.harding@med.monash.edu.au

Supported by Grant 990080 from the National Health and Medical Research Council of Australia.

DOI: 10.1023/01.PDR.0000017485.64723.0A the pulmonary airways and that these changes may persist into later life $(9,10)$. In a study of people born during the Dutch famine of 1944-1945, an association was shown between exposure to famine in mid- and early gestation and obstructive airways disease in adulthood (11). This observation supports the hypothesis that fetal undernutrition during critical periods of development in utero can permanently alter the structure and function of the airways.

Despite evidence that restriction of fetal growth impacts upon lung development $(12,13)$, there have been few studies on the effects of growth restriction on airway development. One study examined the tracheal structure of fetal sheep after restriction of fetal growth induced by the restriction of placental growth (14). Near to term, the tracheas of growth-restricted 
fetuses were found to have thinner mucosal and submucosal layers, reduced ciliation of epithelial cells, and a reduced extent of mucosal folding. Although this study (14) showed that IUGR could induce structural alterations in the fetal trachea, there appear to have been no studies of the effects of IUGR on more distal airways, nor of postnatal airway structure after IUGR to determine whether alterations persist into postnatal life.

Therefore, the objectives of this study were to characterize the effects of IUGR on the structure of pulmonary airways in the near-term fetus and to determine whether observed alterations in airway structure persist after birth. Our hypothesis was that late-gestational IUGR would alter the structure of the airways at birth and that changes would persist into postnatal life. We have also examined bronchial submucosal glands and mucosal mucus in fetal and postnatal airways, as a previous study indicated that their development in the fetal trachea may be impaired by IUGR (14). This is of interest because airway mucus provides airway defense, and the incidence of respiratory infections during infancy is increased by $\operatorname{IUGR}(15,16)$. In the present study, we induced IUGR by chronic embolization of the umbilical-placental circulation (17).

\section{METHODS}

Pulmonary airways from 20 fetal and postnatal lambs of the same breed (Border Leicester $\times$ Merino) were used. Near-term fetuses ( $140 \mathrm{~d}$ of gestation, term being $\sim 147 \mathrm{~d}$ ) constituted the fetal groups. These groups were comprised of five controls (three twins, two singletons) and five IUGR fetuses (four twins, one singleton). Animals forming the postnatal groups were born spontaneously at term and were humanely killed at $8 \mathrm{wk}$ after birth. The composition of these groups were five singleton control lambs and five twin IUGR lambs. The study was approved by the Animal Welfare Committee of Monash University.

Surgical preparation. Pregnant sheep providing both groups of fetuses and lambs underwent surgery for the chronic implantation of catheters at $116 \pm 1 \mathrm{~d}$ (mean \pm SEM) after mating. Anesthesia of mother and fetus was induced by thiopentone $(20 \mathrm{mg} / \mathrm{kg}$ iv) and maintained, after intubation, with halothane ( $1.5 \%$ to $2 \%$ in oxygen). In each fetus, a catheter was inserted into the descending aorta via a femoral artery such that its tip lay between the renal arteries and the common umbilical artery (17). This catheter was used for blood sampling and for the injection of microspheres to embolize the umbilicalplacental vascular bed.

Umbilical-placental embolization. Restriction of fetal growth was induced by placental embolization (17) from 120 to $140 \mathrm{~d}$ after mating in the prenatal group and from $120 \mathrm{~d}$ to the onset of labor in the postnatal group. Insoluble, nonradioactive microspheres (40-70 $\mu \mathrm{m}$, Sephadex G-25, Pharmacia LKB, Uppsala, Sweden) were injected daily into the fetal aorta so as to cause an approximate halving of fetal $\mathrm{SaO}_{2}$. Control fetuses received daily saline injections with no microspheres.

Postmortem tissue collection. At $140 \mathrm{~d}$ of gestation, animals comprising the fetal group were killed (pentobarbital, iv) and the lungs removed. The right lung was fixed at $20 \mathrm{~cm} \mathrm{H}_{2} \mathrm{O}$ via the trachea for $24 \mathrm{~h}$ using $4 \%$ paraformaldehyde and $0.2 \%$ glutaraldehyde. Postnatal lambs were killed (pentobarbital, iv) at 8 wk after birth and their lungs fixed as with fetal lungs.

Airway analysis. We cut transverse sections of identified generations of major airways, from the trachea (generation 0), the lobar bronchus (generation 1), and segmental bronchus (generation 2) to the smaller conducting bronchi (generation 8) using the notation of Burri (18). The analysis involved systematic sampling of airways within both groups of sheep, allowing for a direct comparison between identical airway generations; hence, it was not biased toward any particular airway. Intrapulmonary airways were dissected from both the cranial and caudal lobes of the right lung. Because it was technically difficult to accurately identify and dissect beyond generation 8 , samples of lung parenchyma were removed to examine the structure of bronchioles. For morphometric analysis, sections of airways and lung parenchyma were paraffin-embedded and $5-\mu \mathrm{m}$ sections cut and stained with hematoxylin and eosin in duplicate. Stained sections were examined using a video-linked microscope (Leica Laborlux, Wetzlar, Germany). Digital images were stored (Image Pro Plus version 3.0) and morphometric measurements made using the SCION image analysis program (National Institutes of Health, Bethesda, MD, U.S.A.). All measurements were made on coded slides, thereby blinding the observer to the case classification. Withinobserver variability was expressed as the coefficient of variation calculated for 10 measurements made on the same airway (19); this value was $1.5-1.6 \%$.

Bronchioles in the lung parenchyma were divided into two groups based on their values of $\mathrm{P}_{\mathrm{bm}}$ and subjected to the same analysis as bronchi. Bronchioles with a $\mathrm{P}_{\mathrm{bm}}$ of $<1 \mathrm{~mm}$ were arbitrarily classified as group $\mathrm{A}$, and those with a $\mathrm{P}_{\mathrm{bm}}>1 \mathrm{~mm}$ were classified as group B.

Airway morphometry. We used an established method to analyze the structure of airways (20) as shown in Figure 1. The luminal area of the airway $\left(\mathrm{A}_{\text {inep }}\right)$ was the area enclosed within the internal perimeter of the epithelium $\left(\mathrm{P}_{\text {inep }}\right)$. The perimeter of the basement membrane $\left(\mathrm{P}_{\mathrm{bm}}\right)$ was measured and the area within this perimeter $\left(\mathrm{A}_{\mathrm{bm}}\right)$ was used in the calculation of epithelial area (see below). We also measured the inner perim-

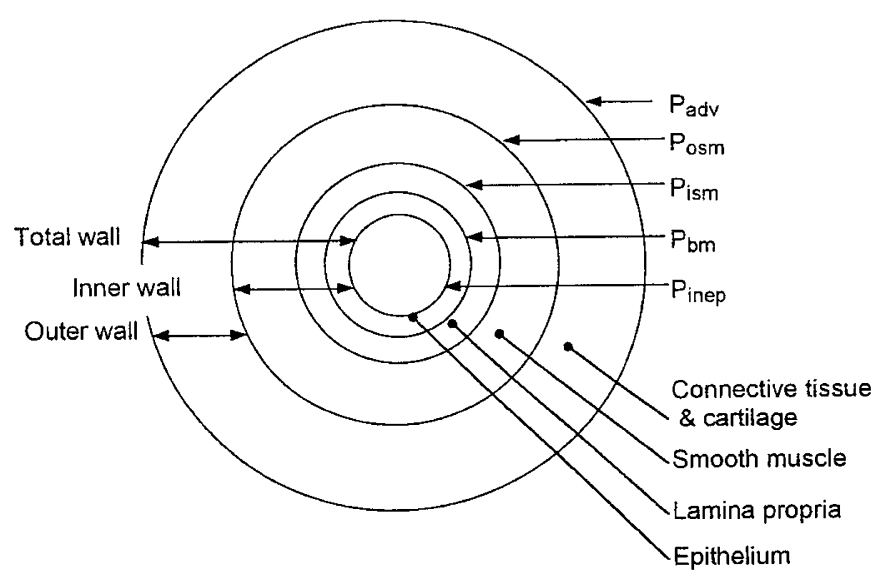

Figure 1. Schematic representation of the airway wall components and their boundaries. 
eter of the smooth muscle layer $\left(\mathrm{P}_{\text {ism }}\right)$; the area enclosed within this perimeter $\left(\mathrm{A}_{\mathrm{ism}}\right)$ was used in the calculation of smooth muscle area. The outer perimeter of the smooth muscle layer $\left(\mathrm{P}_{\text {osm }}\right)$ defines the boundary between the inner and outer airway wall; the area enclosed within this perimeter $\left(\mathrm{A}_{\mathrm{osm}}\right)$ was used in the calculation of the areas of the smooth muscle, and the inner and outer wall of the airway. The outer perimeter of the airway adventitia $\left(\mathrm{P}_{\text {adv }}\right)$ was measured, and the area within this perimeter $\left(\mathrm{A}_{\mathrm{adv}}\right)$ was used in the calculation of the outer wall area. The area of cartilage $\left(\mathrm{A}_{\text {cart }}\right)$ was calculated by summing the areas of cartilage within each section. Other areas calculated were the inner wall area $=A_{\text {osm }}-A_{\text {inep }}$; the outer wall area $=A_{\text {adv }}-A_{\text {osm }}$; the epithelial area $=A_{b m}-A_{\text {inep }}$; the smooth muscle area $=A_{\text {osm }}-A_{\text {ism }}$; and the total wall area $=$ inner wall area + outer wall area.

Measurements of areas of airway wall components were expressed in relation to the $\mathrm{P}_{\mathrm{bm}}$. $\mathrm{P}_{\mathrm{bm}}$ was used to standardize airway wall measurements because it is not affected significantly by changes in lung volume or smooth muscle contraction $(20,21)$. To quantify the degree of mucosal folding, a folding index was derived by dividing the $\mathrm{P}_{\text {inep }}$ by the square root of the area of the lumen area $\left(\sqrt{ } A_{\text {inep }}\right)(22)$.

We measured the number of alveolar attachment sites on bronchioles; these are the points at which alveolar walls are radially attached to the outer wall of the nonrespiratory bronchioles (23). They are of interest because they are considered to be functionally analogous to the structural support given to the larger airways by cartilage. An index of alveolar attachment density was calculated by dividing the number of alveolar attachments around the adventitial border of an airway by $\mathrm{P}_{\mathrm{adv}}$.

Submucosal gland profiles were counted in sections (stained with Masson's trichrome) of bronchial generations 2, 4, and 6 from the cranial and caudal lobes of the right lungs from fetuses and postnatal lambs. We counted only those gland profiles in which a lumen was surrounded by a ring of epithelial cells. Counts of gland profiles, expressed in relation to $\mathrm{P}_{\mathrm{bm}}$, from the two lobes were combined before analysis.

We measured the area of mucin in the epithelial layer of airway generations 2-7 (cranial and caudal lobes) stained with Alcian blue and periodic acid-Schiff (AB/PAS). The area of epithelial mucin included intracellular mucosubstances as identified by $\mathrm{AB} / \mathrm{PAS}$ staining; extracellular secretions were not included. To determine the volume of mucin in the epithelium of each airway generation examined, single fields from four quadrants of each airway cross-section were captured using an Olympus BH2 microscope at $400 \times$ magnification. All images were captured using a camera system (Dage MTI, Michigan City, Indiana, U.S.A.) interfaced to a MacIntosh 8100 computer. The area of intracellular mucin in each field was determined using the density gradient function of the stereology NIH Image program (National Institutes of Health) to highlight stained mucosubstances. The area of mucin within the epithelium was expressed in relation to $\mathrm{P}_{\mathrm{bm}}$, which was also measured using NIH Image program.

Data analysis. Morphometric measurements from the larger airways (i.e. generations $0-8$ ) were analyzed using a repeated two-way ANOVA, with treatment (control versus IUGR) and airway generation $(0-8)$ as between and repeated factors, respectively. Data from the upper and lower lobes of the lung were combined and averaged for this analysis. The effects of IUGR on dimensional measurements from bronchioles were analyzed using the unpaired $t$ test. Values are expressed as mean \pm SEM. Statistical significance was accepted at $p<$ 0.05 .

\section{RESULTS}

\section{Data from Fetuses}

Blood data. During the period of placental embolization, IUGR fetuses had lower $\mathrm{PaO}_{2}$ and $\mathrm{SaO}_{2}$ values $(13.2 \pm 0.8 \mathrm{~mm}$ $\mathrm{Hg}$ and $29.2 \pm 1.7 \%$, respectively) than controls $(18.9 \pm 1.3$ $\mathrm{mm} \mathrm{Hg}$ and $49.9 \pm 3.4 \%$, respectively). Fetal $\mathrm{PaCO}_{2}$ (47.2 \pm $1.5 \mathrm{~mm} \mathrm{Hg})$ and $\mathrm{pHa}(7.37 \pm 0.01)$ were not different between IUGR and control groups. Blood glucose concentrations were lower in IUGR fetuses than in controls $(0.4 \pm 0.0$ versus $0.7 \pm$ $0.0 \mathrm{mmol} / \mathrm{L}, p<0.05)$, whereas lactate concentrations were not different between groups $(0.9 \pm 0.1 \mathrm{mmol} / \mathrm{L})$.

Body and organ weights. At postmortem (140 d of gestation), body weights of IUGR fetuses were $37 \%$ lower than those of controls $(p<0.05)$. Lung weights tended to be lower in IUGR fetuses than in controls $(p=0.08)$; however, when adjusted for body weight there was no significant difference between groups (Table 1).

Structure of trachea and bronchi. In both groups of fetuses, $\mathrm{P}_{\mathrm{bm}}$ and the luminal area of airways progressively decreased from the trachea to generation 8 (Fig. 2A, B). In IUGR fetuses, both $\mathrm{P}_{\mathrm{bm}}(p<0.01)$ and luminal areas $(p<0.04)$ of these airways were smaller than in control fetuses (Fig. 2A, B).

Between airway generations $0-8$, the inner wall area, in relation to $\mathrm{P}_{\mathrm{bm}}$, tended to be smaller in IUGR fetuses than in controls $(p=0.09$, Fig. $3 A)$. The area of the outer airway wall of IUGR fetuses, and hence the total wall area (both adjusted for $\mathrm{P}_{\mathrm{bm}}$ ) were significantly smaller than in controls (both $p<$ 0.02 , Fig. 3, $B$ and $C$ ). The areas of epithelium and cartilage, in relation to $\mathrm{P}_{\mathrm{bm}}$, were significantly smaller in IUGR fetuses ( $p$ $<0.02$ and $p<0.05$ respectively; Fig. 4), whereas there was no difference in the area of smooth muscle between groups. Between airway generations $0-8$, IUGR fetuses tended $(p=$

Table 1. Body and lung weights in fetuses aged $140 d$ of gestation and 8-wk-old lambs after birth

\begin{tabular}{lcc}
\hline & Controls $(n=5)$ & IUGR $(n=5)$ \\
\hline Fetuses & & \\
$\quad$ Body weight $(\mathrm{kg})$ & $4.38 \pm 0.27$ & $2.74 \pm 0.18^{*}$ \\
Wet lung weight $(\mathrm{g})$ & $128.6 \pm 9.4$ & $95.4 \pm 14.0 \dagger$ \\
Adjusted wet lung weight $(\mathrm{g} / \mathrm{kg})$ & $29.3 \pm 0.9$ & $34.5 \pm 3.5$ \\
\hline Postnatal lambs & & \\
GA at birth $(\mathrm{d})$ & $146 \pm 1$ & $145 \pm 1$ \\
Birth weight $(\mathrm{kg})$ & $4.62 \pm 0.24$ & $2.54 \pm 0.26^{*}$ \\
Body weight at 8 wk $(\mathrm{kg})$ & $16.20 \pm 1.66$ & $11.90 \pm 2.54 \ddagger$ \\
Wet lung weight $(\mathrm{g})$ & $235.4 \pm 20.7$ & $175.2 \pm 29.8$ \\
Adjusted wet lung weight $(\mathrm{g} / \mathrm{kg})$ & $14.7 \pm 0.8$ & $14.5 \pm 2.9$ \\
\hline
\end{tabular}

GA, gestational age.

* SD between control and IUGR groups $(p<0.05)$.

$\dagger p=0.08$.

$\ddagger p=0.07$. 

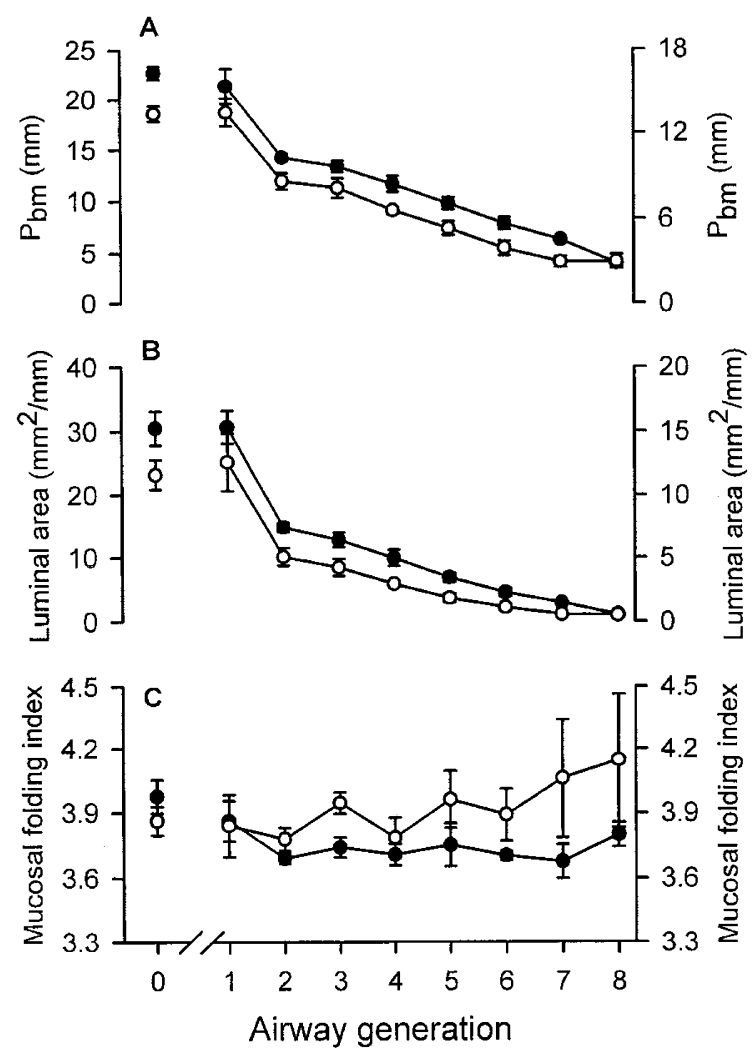

Figure 2. Mean \pm SEM values of $(A)$ basement membrane perimeter $\left(\mathrm{P}_{\mathrm{bm}}\right)$; $(B)$ luminal area, adjusted for $\mathrm{P}_{\mathrm{bm}}$; and $(C)$ mucosal folding index in the airways of control fetuses (filled symbols, $n=5$ ) and IUGR fetuses (open symbols, $n=5$ ) at $140 \mathrm{~d}$ of gestation. $\mathrm{P}_{\mathrm{bm}}$ and luminal areas (adjusted for $\mathrm{P}_{\mathrm{bm}}$ ) declined with airway generation and were significantly lower in IUGR fetuses than in controls. The mucosal folding index tended to be greater $(p=0.07)$ in IUGR fetuses compared with controls. Left-hand scale relates to trachea (generation 0 ) and right-hand scale relates to generations 1-8.

$0.07)$ to have a greater degree of mucosal folding compared with controls (Fig. 2C).

The numbers of submucosal gland profiles in bronchial airways were not significantly different between IUGR and control fetuses (Fig. 5). Similarly, the volume of epithelial mucin, in relation to $\mathrm{P}_{\mathrm{bm}}$, in the upper and lower lobes was not different between groups (Fig. 5).

Bronchioles. Between IUGR and control fetuses, no differences were found in both groups $\mathrm{A}\left(\mathrm{P}_{\mathrm{bm}}<1 \mathrm{~mm}\right)$ or $\mathrm{B}\left(\mathrm{P}_{\mathrm{bm}}>1\right.$ $\mathrm{mm})$ bronchioles in luminal area, the number of alveolar attachments (both expressed in relation to $\mathrm{P}_{\mathrm{bm}}$ ), and in the mucosal folding index.

\section{Data from Postnatal Lambs}

Prenatal blood data. During the prenatal embolization period, IUGR animals studied postnatally had lower values of $\mathrm{PaO}_{2}$ and $\mathrm{SaO}_{2}(14.8 \pm 0.8 \mathrm{~mm} \mathrm{Hg}$ and $35.8 \pm 2.9 \%$, respectively) than in controls $(21.4 \pm 0.9 \mathrm{~mm} \mathrm{Hg}$ and $56.6 \pm 1.5 \%$, respectively). In these IUGR fetuses, $\mathrm{pH}$ was lower than in controls $(7.34 \pm 0.01$ versus $7.37 \pm 0.01)$ and $\mathrm{PaCO}_{2}$ was higher $(53.1 \pm 0.9$ versus $47.2 \pm 1.5 \mathrm{~mm} \mathrm{Hg})$. Fetal blood glucose concentrations tended to be lower in IUGR fetuses than in controls $(0.5 \pm 0.1$ versus $0.7 \pm 0.0 \mathrm{mmol} / \mathrm{L}, p=0.16)$
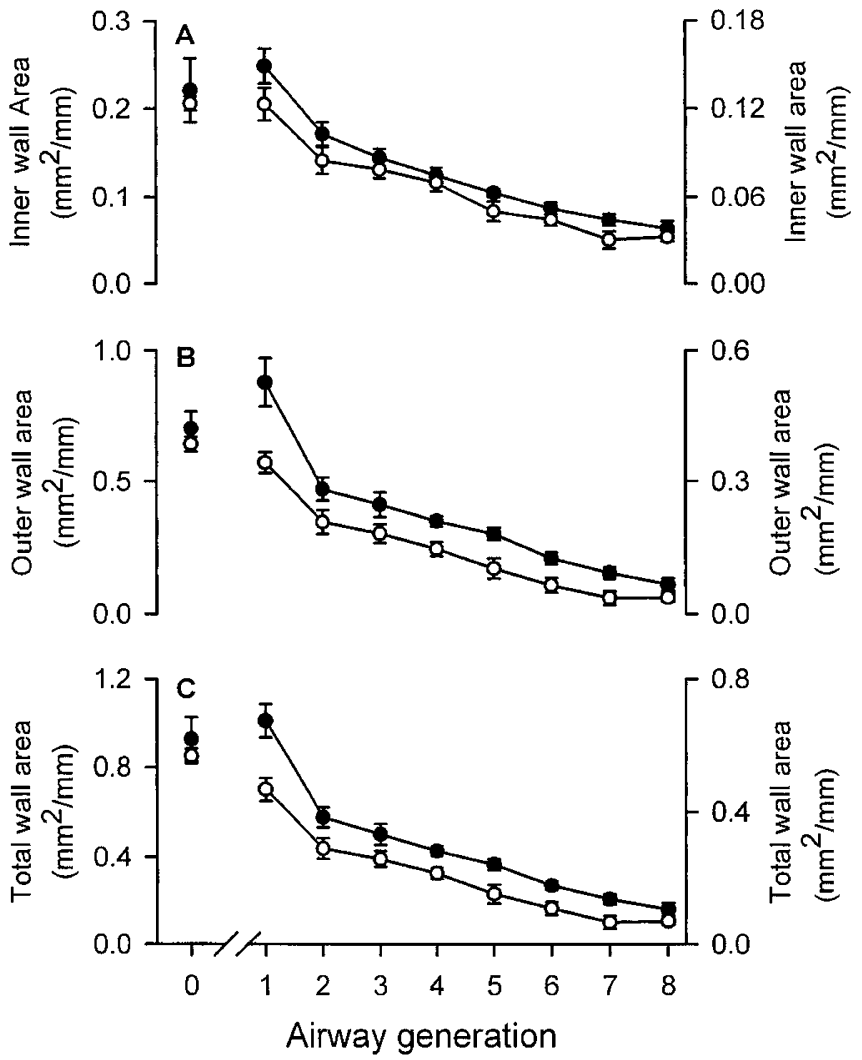

Figure 3. Mean \pm SEM values of $(A)$ inner wall area, $(B)$ outer wall area, and (C) total wall area (all adjusted for $\mathrm{P}_{\mathrm{bm}}$ ) of the airways of control fetuses (filled symbols, $n=5$ ) and IUGR fetuses (open symbols, $n=5$ ) at $140 \mathrm{~d}$ of gestation. The adjusted area of the inner airway wall tended to be smaller in IUGR fetuses than controls $(p=0.09)$. The adjusted area of the outer airway wall and the entire wall (inner plus outer) were significantly smaller in IUGR fetuses than controls. Left-hand scale relates to trachea (generation 0) and right-hand scale relates to generations $1-8$.

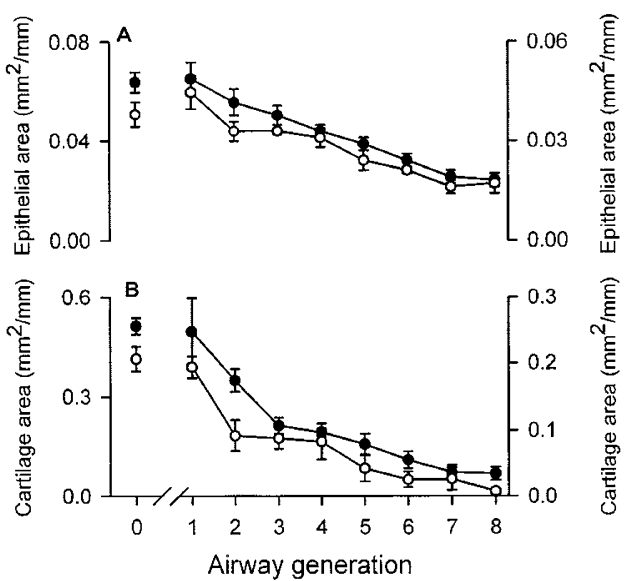

Figure 4. Mean \pm SEM values of $(A)$ epithelial area and $(B)$ area of cartilage, both adjusted for $\mathrm{P}_{\mathrm{bm}}$, of the airways of control fetuses (filled symbols, $n=5$ ) and IUGR fetuses (open symbols, $n=5$ ) at $140 \mathrm{~d}$ of gestation. The adjusted areas of airway epithelium and cartilage were both significantly smaller in IUGR fetuses than in controls. Left-hand scale relates to trachea (generation 0) and right-hand scale relates to generations $1-8$.

and arterial lactate levels were lower in the IUGR fetuses $(0.8$ \pm 0.0 versus $0.9 \pm 0.0 \mathrm{mmol} / \mathrm{L}, p=0.01$ ).

Postnatal growth data. All lambs were born at term, and birth weights of IUGR lambs were $45 \%$ lower than those of 
controls (Table 1). At $8 \mathrm{wk}$ after birth, body weights of IUGR lambs tended to be lower (by 26.5\%) than those of controls ( $p$ $=0.07$ ), suggesting a relative catch-up in body weight by 8 wk. Lung weights of IUGR lambs were not significantly different from those of control lambs; when adjusted for body weight, values were also not different (Table 1).

Airway structure. As in fetuses, $\mathrm{P}_{\mathrm{bm}}$ and luminal area of postnatal airways progressively decreased from the trachea to generation 8. No differences were found between control and IUGR postnatal lambs in $\mathrm{P}_{\mathrm{bm}}$, airway luminal areas, mucosal folding index, or any of the measured dimensions of the larger airways (generations $0-8$ ). In both classes of bronchioles, there was no significant difference between the treatment groups in wall dimensions or numbers of bronchiolar-alveolar attachments, expressed in relation to $\mathrm{P}_{\mathrm{adv}}$.

Compared with controls, there was a significantly smaller number of submucosal gland profiles, expressed in relation to $\mathrm{P}_{\mathrm{bm}}$, in the bronchi of postnatal IUGR lambs (Fig. $5 A$ ). In contrast, there was a greater area of epithelial mucin, relative to $\mathrm{P}_{\mathrm{bm}}$, in the IUGR lambs than in controls (Fig. 5B). Epithelial mucin and submucosal glands in a second generation airway of an 8-wk-old postnatal lamb previously subjected to IUGR are shown in Figure 6.

Airway growth. In IUGR animals, the luminal areas of airway generations $0-4$ significantly increased after birth;
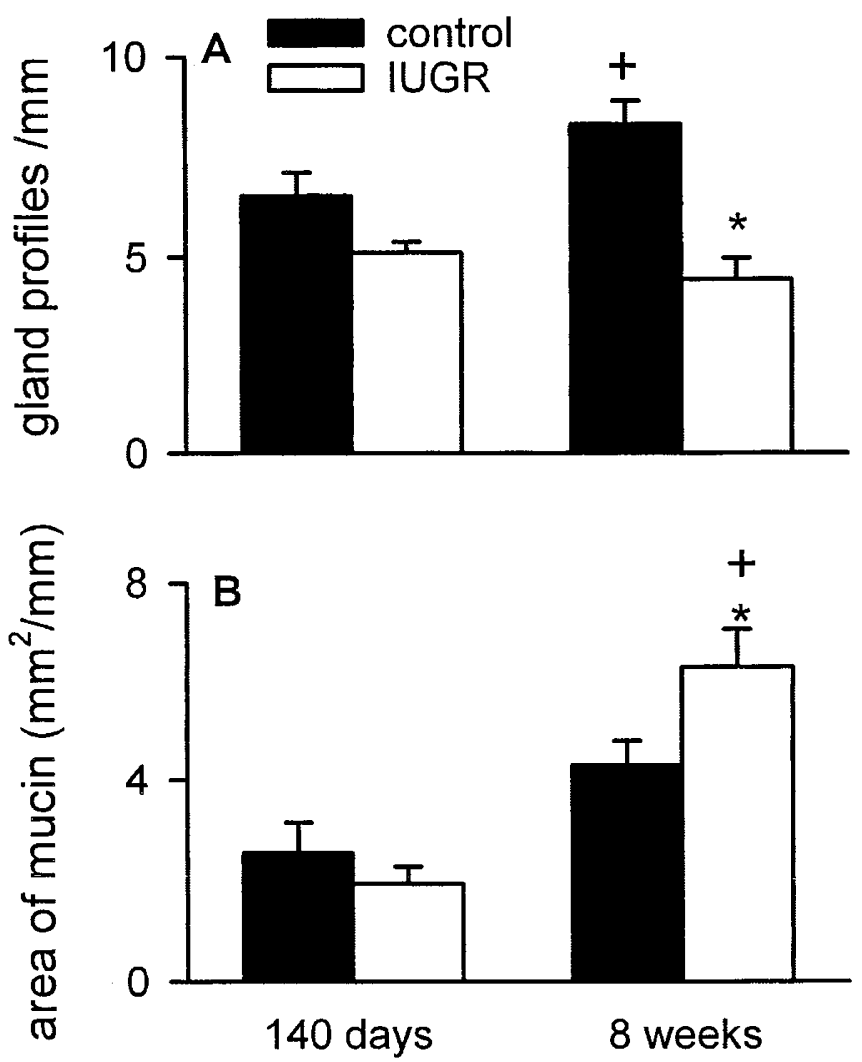

Figure 5. Mean \pm SEM values of $(A)$ submucosal gland density (gland profiles $/ \mathrm{mm}$ $\left.\mathrm{P}_{\mathrm{bm}}\right)$ and $(B)$ area of mucosal mucin $\left(\mathrm{mm}^{2} / \mathrm{mm} \mathrm{P}_{\mathrm{bm}}\right)$ in airway generations 2,4 , and 6 of control and IUGR fetuses and postnatal lambs. In fetuses, the volume of epithelial mucin and submucosal gland density were not significantly different between groups. In postnatal lambs, the volume of mucin was significantly greater and gland density was significantly smaller in IUGR lambs compared with controls. $* p<0.05$ (IUGR $v s$ control). $+p<0.05$ ( 8 weeks $v s$ control).

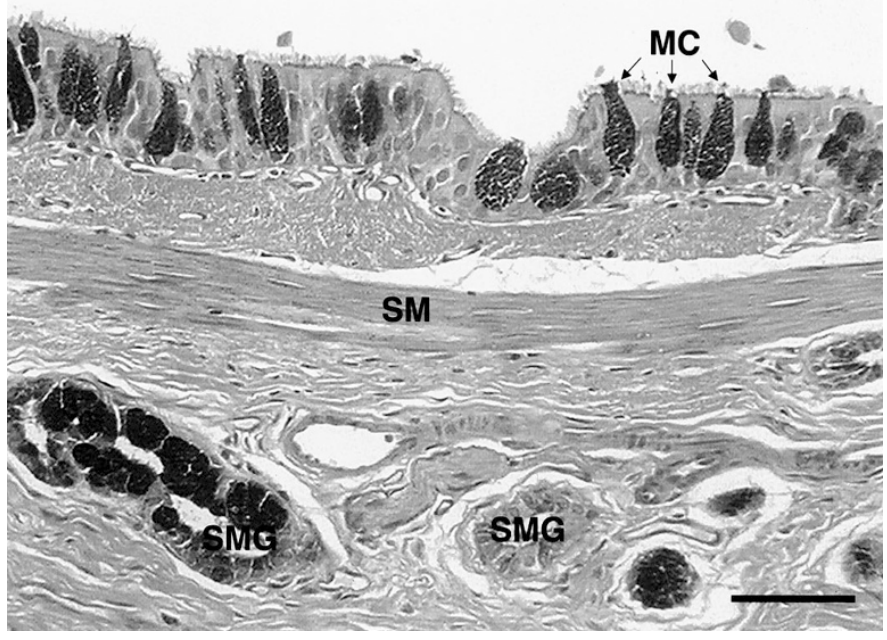

Figure 6. Micrograph of a second-generation airway wall from an 8-wk-old postnatal lamb previously subjected to IUGR (Masson's stain). Numerous mucin-containing cells $(M C)$ line the airway surface. Submucosal glands $(S M G)$ are present below a band of smooth muscle $(S M)$. Scale bar: $50 \mu \mathrm{m}$.

similar changes with age were seen in controls but, with the exception of generations 0 and 2, they were not significant (Fig. 7A). In control animals, but not in those exposed to IUGR, the luminal areas of the smallest airways examined (generations 7 and 8) were significantly smaller after birth (Fig. $7 A$ ); a similar trend was seen in generations 5 and 6 of controls and generation 8 of IUGR animals. In airway generations $1-7$, the age-related increase in luminal area was greater in IUGR animals than in controls (Fig. $7 A$ ).

In IUGR animals, the wall areas of airway generations $0-8$ increased with age (Fig. 7B). In generations 1-8, the increases with age in airway wall area were greater in the IUGR group than in controls (Fig. 7B).

\section{DISCUSSION}

We have used a rigid sampling scheme to compare identical airway generations (from 0 to 8 ) using an unbiased analysis to reveal morphometric changes during fetal growth restriction as well as persistent alterations after postnatal recovery and compensatory growth. Chronic placental insufficiency during late gestation affected tracheal and bronchial structure in the nearterm fetus; in particular, the walls of the trachea and larger bronchi were thinner, relative to their $\mathrm{P}_{\mathrm{bm}}$, confirming earlier observations on the effects of IUGR on the fetal sheep trachea (14). At the time of imposing the placental restriction ( 0.8 of term), the airways would have been growing and structurally maturing and those processes were apparently affected by the intrauterine factors that restricted fetal growth. An unexpected finding was that most of the structural alterations observed in airway walls of the IUGR fetuses near to term were not apparent at $8 \mathrm{wk}$ after birth, indicating that the major airways had largely recovered from prenatal growth deficits. Thus, our hypothesis that IUGR would cause persistent changes in airway structure was not substantiated, apart from alterations observed in mucus elements. 

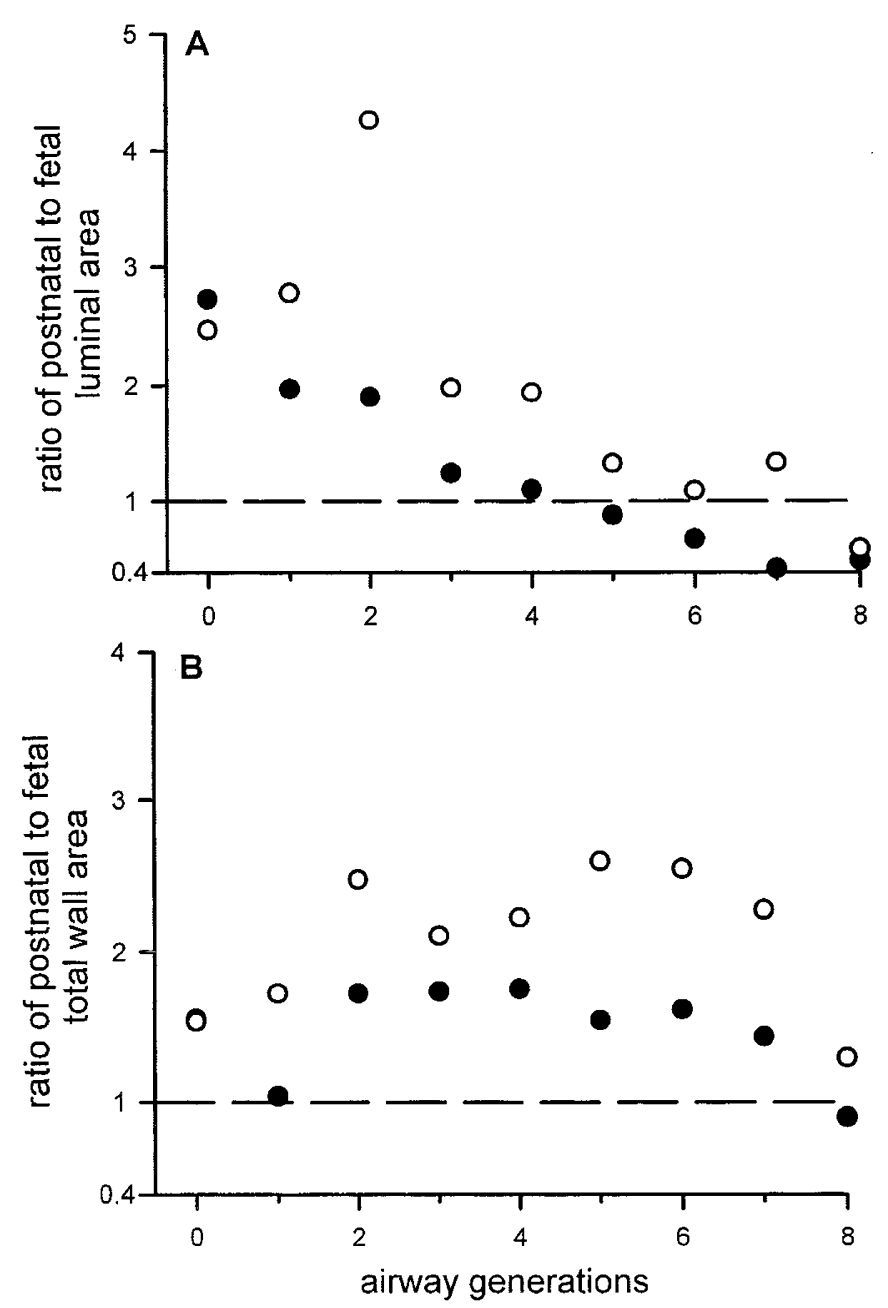

Figure 7. Changes with age, from $140 \mathrm{~d}$ of gestation to $8 \mathrm{wk}$ after birth, in the mean luminal areas $(A)$ and relative total airway wall thicknesses $(B)$ of airways between the trachea (generation 0 ) and generation 8. Data are expressed for both IUGR (open circles) and control animals (filled circles) as ratios of values in 8-wk-old lambs to those in 140-d-old fetuses. (A) In IUGR animals, the luminal areas of generations $0-4$ significantly increased after birth; similar trends were seen in controls. In control animals, the luminal areas of generations 7 and 8 became significantly smaller after birth. The age-related increase in luminal area was greater in IUGR animals than in controls (generations 1-7). (B) In both groups, the total airway wall areas increased with age, the increases being greater in the IUGR group than in controls.

The smaller values of $\mathrm{P}_{\mathrm{bm}}$ and luminal area for the trachea and larger bronchi (generations 1-8) of IUGR fetuses are consistent with the tendency for lung weights to be smaller in these fetuses. However, the significant reductions in airway wall thicknesses observed in IUGR fetuses were not simply due to their lungs being smaller, as the areas of the airway wall components were normalized by relating them to $\mathrm{P}_{\mathrm{bm}}$. The significant reductions in airway wall dimensions of IUGR fetuses, adjusted for $\mathrm{P}_{\mathrm{bm}}$, suggests that these dimensions may have been reduced in relation to lung (and body) weights. Our finding that IUGR led to fetal airways having thinner walls with less cartilage, in relation to $\mathrm{P}_{\mathrm{bm}}$, suggests that IUGR neonates born at term would have more compliant, and hence more collapsible, airways. This could contribute to the greater vulnerability to respiratory illness of infants born small for gestational age (24), as evidence of increased airway compliance has been associated with wheezing disorders in infants (25).

Many preterm infants have been exposed to IUGR (26), and in these infants the risk of neonatal death and respiratory distress is greater than in normally grown preterm infants (2). Our data suggest that airway dimensions and their mechanical properties in preterm neonates following IUGR may be more severely affected than in IUGR neonates born at term as airway compliance decreases with age (27-29). The thinner-walled airways of the preterm infant are more likely to sustain deformational changes than less compliant, more mature airways. In part, this may be due to a reduced amount of cartilage, which in the sheep (29) and other species $(30,31)$ has been associated with increased airway compliance. Such changes in airway properties may contribute to the increased risk of respiratory illness and death in infants affected by both preterm birth and IUGR (2).

Our observation that, in fetuses subjected to IUGR, the dimensions of the larger airways were affected suggests that, in contrast to the smaller, noncartilaginous bronchioles, the cartilaginous airways may be vulnerable to chronic fetal undernutrition and hypoxemia. In sheep, the large airways contain cartilage as well as glandular, muscular, vascular, and neural elements in their walls from as early as $40 \mathrm{~d}$ of gestation (32). As found in an earlier study of the trachea of growth-restricted fetuses (14), cartilage was the component of fetal bronchial walls most adversely affected by IUGR. It is not known why cartilage was preferentially affected compared with other airway wall components, but IUGR could impact upon the growth of cartilage and other airway wall structures by a) restriction of nutrient or oxygen supply or b) catabolic processes associated with $\operatorname{IUGR}(33,34)$.

Airway smooth muscle is present and is functional from early in gestation (35). Smooth muscle may be important in early airway development as its contraction has been shown to stiffen the neonatal airways (36), rendering them less likely to collapse. In the preterm ovine trachea, a reduction, compared with term controls, in smooth muscle contractility has been observed, possibly contributing to an inability of the trachea to resist collapse (28). In our study, no differences in the areas of tracheal and bronchial smooth muscle were observed between control and IUGR fetuses. However, as smooth muscle contractility was not examined, it is not possible to know whether mechanical properties of airways were affected.

The degree of mucosal folding is of potential importance as it has been suggested that folding may enhance structural support of small airways, thereby resisting collapse (37). The increased mucosal folding in the airways of IUGR fetuses ( $p=$ 0.07) may have been due to their thinner walls, and this is supported by the tendency for these airways to have smaller luminal areas. It is possible that the bronchial airways were more severely folded in vivo in IUGR fetuses, and fixing the lungs at a constant pressure may have attenuated the degree of airway collapse and folding. Thus, fixing the lungs at their volume in vivo, rather than at a fixed pressure, may have provided a clearer indication of the state of the airways in vivo. The increased folding we observed in the airways of IUGR 
fetuses could be a result of the thinner airway wall in these fetuses, or a response to an increased tendency to collapse.

The postnatal IUGR lambs showed evidence of catch-up growth in that, compared with controls, there was a greater proportional increase in their body weights between birth and 8 wk (IUGR, 468\%, versus control, 350\%). At 8 wk, lung weights remained proportional to body weights. In contrast to our findings in fetuses, at $8 \mathrm{wk}$ after birth the bronchi of IUGR lambs possessed comparable luminal areas and relative wall thicknesses to those of control lambs, suggesting that catch-up growth of the airways had occurred after birth. The absence of chronic hypoxemia and hypoglycemia (13) after birth could have accounted for the apparent acceleration in airway growth. It is possible that, in the animals studied after birth, alterations in airway structure induced by IUGR may have been greater at the time of birth than those observed at $140 \mathrm{~d}$ of gestation, as the period of placental insufficiency was approximately $5 \mathrm{~d}$ longer. Thus, the degree of structural recovery may have been greater than that observed by comparing airways of 140 -d-old fetuses and 8-wk-old animals. Although there were no differences between treatment groups in airway morphometry at 8 wk, our other studies in lambs subjected to IUGR have shown that persistent changes were present in aspects of lung function (13) and alveolar structure (12). It is possible that such alterations could account for some of the detrimental effects of IUGR on respiratory function reported in epidemiologic studies.

Our IUGR groups contained a preponderance of twins, as it was considered that twinning may enhance the growth restriction induced by placental embolization. Although there is some evidence that twinning impairs lung function (5), we know of no evidence that airway structure is affected by twinning per $s e$. It is possible that some alterations of airway wall structure observed in our IUGR fetuses were due, at least in part, to the growth restricting effects of twinning. However, in postnatal animals, twinning had no apparent effects on airway dimensions.

Growth of the bronchi in both control and IUGR lambs between $140 \mathrm{~d}$ of gestation and $8 \mathrm{wk}$ after birth was disproportionate, with the greatest proportional increases in luminal area occurring in the trachea, and to a lesser extent with successively smaller generations. In control animals, there was little evidence of airway growth (luminal area and relative wall thickness) in airway generations $4-8$ between late gestation and $8 \mathrm{wk}$ after birth. Indeed, the luminal areas of the smaller airways were reduced after birth. The reasons for this disproportionate growth are unclear, but it is apparent that extrapulmonary airways grow more than those within the lungs. This could be a result of increased elastic recoil of the lungs in the postnatal air-filled lung as compared with the liquid-filled fetal lung in which elastic recoil is small owing to the absence of an alveolar air-liquid interface.

Although postnatal growth allowed for substantial recovery from prenatal growth deficits in IUGR-affected animals, clear, albeit subtle, alterations persisted in the form of a rearrangement of mucin-bearing cells and their location in the airway wall. These alterations would significantly affect the anatomical source of mucin supplying the airways. Such alterations may a) change the amount of mucin available to form the mucous lining layer of the airways, b) alter the composition of the mucin due to differences in the makeup of mucin secreted from submucosal glands versus airway goblet cells, or c) alter the normal balance and proportion of epithelial cells lining the airways. Altered secretory activity of the airways could contribute to the increased incidence of respiratory tract infections and illnesses among infants and children of low birth weight $(16,38)$.

Our observation of decreased submucosal gland development in the bronchi of IUGR animals is consistent with findings from a study using a different model of ovine IUGR in which the number of tracheal submucosal glands were decreased in late gestation fetuses (14). It is not clear why IUGR impairs the development of submucosal glands, but prenatal hypoxemia and prenatal and perhaps early postnatal restriction of nutrient availability during a period of glandular development could be involved.

With regard to epithelial mucin, our inability to detect differences in the bronchi of our IUGR fetuses does not appear to be consistent with the study by Rees et al. (14), who found that goblet cells were increased in density in the lower trachea of IUGR fetuses compared with controls. As cellular differentiation and maturation occurs in a wavelike pattern from proximal to distal airways, the differences observed between the trachea and bronchi in IUGR fetuses may be due to differences in airway development. Our finding of an increased density of bronchial mucosal mucin at 8 wk after birth in IUGR lambs is, however, consistent with a previous finding of increased density of goblet cells in the lower trachea in growthrestricted late gestation fetuses (14).

Our findings emphasize the importance of critical windows of development of the respiratory system during both pre- and postnatal periods. Elements such as transcription factors or growth mediators that may be affected by hypoxia or nutrient restriction during key periods of development could have a significant impact on the epithelial-mesenchymal trophic unit. Such influences occurring during different stages of mesenchymal-matrix-epithelial formation could directly impact on cells populating both epithelial and submucosal surfaces. Such may be the case in this study. Future studies should be designed to specifically address these issues.

We conclude that placental insufficiency and consequent IUGR leads to thinning of the walls of the larger airways close to term, largely due to impaired cartilage and epithelial development. Such changes could lead to altered mechanical properties of the airways soon after birth, allowing them greater vulnerability to transmural pressures. By $8 \mathrm{wk}$ after birth at term, relative dimensions of the walls of the major airways were restored to normal. However, the airways were not structurally normal, as the development of mucus elements remained altered, possibly contributing to a greater susceptibility to respiratory infections of infants subjected to IUGR. Studies of older animals will be required to determine whether such alterations persist until later in life.

Acknowledgments. The authors thank John Elliot, Belinda Joyce, Samantha Louey, Jennifer Cook, Diana Perez, and Grammatis Tsintzoglou for their assistance. 


\section{REFERENCES}

1. Tyson JE, Kennedy K, Broyles S, Rosenfeld CR 1995 The small for gestational age infant: accelerated or delayed pulmonary maturation? Increased or decreased survival? Pediatrics 95:534-538

2. Bernstein IM, Horbar JD, Badger GJ, Ohlsson A, Golan A 2000 Morbidity and mortality among very-low-birth-weight neonates with intrauterine growth restriction. Am J Obstet Gynecol 182:198-206

3. Minior VK, Divon MY 1998 Fetal growth restriction at term: myth or reality? Obstet Gynecol 92:57-60

4. Rona RJ, Gulliford MC, Chinn S 1993 Effects of prematurity and intrauterine growth on respiratory health and lung function in childhood. BMJ 306:817-820

5. Nikolajev K, Heinonen K, Hakulinen A, Lansimies E 1998 Effects of intrauterine growth retardation and prematurity on spirometric flow values and lung volumes at school age in twin pairs. Pediatr Pulmonol 25:367-370

6. Wjst M, Popescu M, Trepka MJ, Heinrich J, Wichmann HE 1998 Pulmonary function in children with initial low birth weight. Pediatr Allergy Immunol 9:80-90

7. Barker DJP, Godfrey KM, Fall C, Osmond C, Winter PD, Shaheen SO 1991 Relation of birth weight and childhood respiratory infection to adult lung function and death from chronic obstructive airways disease. BMJ 303:671-675

8. Stein CE, Kumaran K, Fall CH, Shaheen SO, Osmond C, Barker DJ 1997 Relation of fetal growth to adult lung function in south India. Thorax 52:895-899

9. Stocks J 1999 Respiratory physiology during early life. Monaldi Arch Chest Dis $54: 358-364$

10. Shaheen S 1997 The beginnings of chronic airflow obstruction. Br Med Bull 53:58-70

11. Lopuhaä CE, Roseboom TJ, Osmond C, Barker DJP, Ravelli ACJ, Bleker OP, van der Zee JS, van der Meulen JHP 2000 Atopy, lung function, and obstructive airways disease after prenatal exposure to famine. Thorax 55:555-561

12. Maritz GS, Cock ML, Louey S, Joyce BJ, Albuquerque CA, Harding R 2001 Effects of fetal growth restriction on lung development before and after birth: a morphometric analysis. Pediatr Pulmonol 32:201-210

13. Joyce BJ, Louey S, Davey MG, Cock ML, Hooper SB, Harding R 2001 Compromised respiratory function in postnatal lambs following placental insufficiency and intrauterine growth restriction. Pediatr Res 50:720-725

14. Rees S, Ng J, Dickson K, Nicholas T, Harding R 1991 Growth retardation and the development of the respiratory system in fetal sheep. Early Hum Dev 26:13-27

15. Martinez FD 1994 Role of viral infections and the inception of asthma and allergies during childhood: could they be protective. Thorax 49:1189-1191

16. McCall MG, Acheson ED 1968 Respiratory disease in infancy. J Chronic Dis 21:349-359

17. Cock ML, Harding R 1997 Renal and amniotic fluid responses to umbilicoplacental embolization for 20 days in fetal sheep. Am J Physiol 237:R1094-R1102

18. Burri PH 1986 Development and growth of the human lung. In: Fishman AP, Cherniack NS, Widdicombe JG, Geiger SR (eds) Handbook of Physiology. American Physiological Society, Bethesda, MD, pp 1-46
19. Carroll N, Lehmann E, Barret J 1996 Variability of airway structure and inflammation in normal subjects and in cases of nonfatal and fatal asthma. Pathol Res Pract $192: 238-248$

20. Elliot J, Vullermin P, Carroll N, James A, Robinson P 1999 Increased airway smooth muscle in sudden infant death syndrome. Am J Respir Crit Care Med 160:313-316

21. Carroll N, Cooke C, James A 1997 The distribution of eosinophils and lymphocytes in the large and small airways of asthmatics. Eur Respir J 10:292-300

22. James AL, Pare PD, Hogg JC 1988 Effects of lung volume, bronchoconstriction and cigarette smoke on morphometric airway dimensions. J Appl Physiol 64:913-919

23. Saetta M, Ghezzo H, Kim WD, King M, Angus GE, Wang N-S, Cosio MG 1985 Loss of alveolar attachments in smokers. Am Rev Respir Dis 132:894-900

24. Bardin C, Zelkowitz P, Papageorgiou A 1997 Outcome of small-for-gestational age and appropriate-for-gestational age infants born before 27 weeks of gestation. Pediatrics 100:E4(abstr)

25. Frey U, Makkonen K, Wellman T, Beardsmore C, Silverman M 2000 Alterations in airway wall properties in infants with a history of wheezing disorders. Am J Respir Crit Care Med 161:1825-1829

26. Lackman F, Capewell V, Richardson B, daSilva O, Gagnon R 2001 The risks of spontaneous preterm delivery and perinatal mortality in relation to size at birth according to fetal versus neonatal growth standards. Am J Obstet Gyncol 184:946953

27. Bhutani VK, Rubenstein SD, Shaffer TH 1981 Pressure-volume relationships of tracheae in fetal, newborn and adult rabbits. Respir Physiol 43:221-231

28. Penn RB, Wolfson MR, Shaffer TH 1988 Effect of smooth muscle tone on the collapsibility of immature airways. J Appl Physiol 65:863-869

29. Deoras KS, Wolfson MR, Searls RL, Hilfer SR, Shaffer TH 1991 Developmental changes in tracheal structure. Pediatr Res 30:170-175

30. McCormack GS, Moreno RH, Mullen JB, Hogg JC, Bert J, Pare PD 1986 Lung mechanics in papain-treated rabbits. J Appl Physiol 60:242-246

31. Thurlbeck WM, Pun R, Toth J, Frazer RG 1974 Bronchial cartilage in chronic obstructive lung disease. Am Rev Respir Dis 109:73-80

32. Alcorn DG, Adamson TM, Maloney JE, Robinson PM 1981 A morphologic and morphometric analysis of fetal lung development in the sheep. Anat Rec 201:655667

33. Robinson JS, Owens JA, Owens PC 1994 Fetal growth and fetal growth retardation. In: Thorburn GD, Harding R (eds) Textbook of Fetal Physiology. Oxford University Press, Oxford, U.K., pp 83-94

34. Battaglia FC 1978 Principal substrates of fetal metabolism: fuel and growth requirements of the ovine fetus. Ciba Found Symp 63:57-74

35. Sparrow MP, Warwick SP, Mitchell HW 1994 Fetal airway motor tone in prenatal lung development in the pig. Eur Respir J 7:1416-1424

36. Koslo RJ, Bhutani VK, Shaffer TH 1986 The role of tracheal smooth muscle contraction on neonatal tracheal mechanics. Pediatr Res 20:1216-1220

37. Lambert RK 1991 Role of bronchial basement membrane in airway collapse. J Appl Physiol 71:666-673

38. Chan KN, Noble-Jamieson CM, Elliman A, Bryan EM, Silverman M 1989 Lung function in children of low birth weight. Arch Dis Child 64:1284-1293 